\title{
Behavioral and cognitive core domains shared between autism spectrum disorder and schizophrenia
}

\author{
Hirofumi Morioka, Yoichi Kawaike, Hisami Sameshima, Shinji Ijichi* \\ Health Service Center, Kagoshima University, Kagoshima, Japan \\ Email: *jiminy@hsc.kagoshima-u.ac.jp
}

Received 27 February 2013; revised 30 March 2013; accepted 10 April 2013

Copyright (c) 2013 Hirofumi Morioka et al. This is an open access article distributed under the Creative Commons Attribution License, which permits unrestricted use, distribution, and reproduction in any medium, provided the original work is properly cited.

\begin{abstract}
Growing genetic evidence including results of genome-wide association studies and whole-genome sequencing is still perplexing scientists in the fields of human complex traits and compels them to reconsider the relationship between autism spectrum disorder (ASD) and schizophrenia. The developmental trajectory of schizophrenia may be characterized by difficulties in "theory of mind" tasks, poor insight or imagination, low empathy level, weak executive function, failure in social judgments, delayed language development, movement mannerisms, motoric rituals, strong preoccupation with unusual objects, bizarre habits, and high intelligence. Most of these characteristics are associated with the standard criteria for ASD and all of them are core domains or endophenotypes of ASD. The diagnosed ASD cases, which were found in individuals with schizophrenia, have a significant tendency to be high-functioning and to have atypical age of ASD manifestation. Episodic features including reality distortion, which can be seen in individual with ASD, may be associated with hyperarousal conditions with cognitive hypersensitivity, misattribution of negative experiences, and the perceptual thinking style. Together with the emerging new genetic concepts concerning human behavioral complex traits, the results and constructions of these recent studies may further warrant that reconsideration of the relationship between ASD and psychotic conditions is necessary. In addition, the possibility that psychotic conditions are the secondary derivative states in individuals with ASD or in individuals with subclinical ASD components should be constructively examined.
\end{abstract}

Keywords: Autism Spectrum Disorder (ASD);

"Corresponding author.
Schizophrenia; Reality Distortion; Psychotic Conditions

\section{INTRODUCTION}

Different perspectives cause distinct perceptions and interpretations of a condition. When the apparent difference among the perceptions or interpretations is recognized to be significant, a single condition could be misunderstood to be multiple separate categorical entities. In the conceptualization of the relation between symptoms and diagnostic categories, latent core structures underpinning the symptoms and causal networks consisting of the symptoms are recognized as important prerequisites for the categorization [1]. Therefore, probing the core domains or structures and considering the interrelationship between the domains may be quite worthwhile to evaluate the categorical identity of conditions.

The categorical identity of a lot of human behavioral and psychiatric conditions is now being compromised by recent results of genetic studies [2-9], twin studies [1014], and endophenotypic reconsideration [15-18]. Such conditions include autism spectrum disorder (ASD), schizophrenia, attention-deficit hyperactivity disorder, learning disorders, obsessive-compulsive disorder, bipolar disorder, major depressive disorder, anxiety disorders, eating disorders, posttraumatic stress disorder, and personality disorders. In this genetic and endophenotypic complexity, ASD and schizophrenia are essential as the prototypic diagnostic categories whose genetic and phenotypic characteristics are being reexamined or compared among these conditions. The distinction between autism and the preceding clinical entity, schizophrenia, had been well attempted and should have already been completed [19]. However, the conviction that the ostensible lack of the first rank schizophrenic symptoms (Schneider) can distinguish autism from the early onset schizophrenia variant only implies that autistic children cannot be categorized as a subset of schizophrenia. Although the age of 
onset had been recognized as an important firm ground for the distinction between autism and schizophrenia [19], the onset age of autism (ASD) in a standard diagnostic criteria (Diagnostic and Statistical Manual of Mental Disorders, DSM) is going to be changed from "prior to age 3 years" (DSM-IV-TR) to "in early childhood" (DSM-5). Significantly, it is additionally documented in DSM-5 that autistic symptoms may not become fully manifest until social demands exceed limited capacities. Therefore, even the taxonomic identity of schizophrenia should be reconsidered and a new insight whether schizophrenia is a subset of ASD should be examined [20-22]. Here we review recent results of studies in relation to behavioral and cognitive core domains shared between ASD and schizophrenia.

\section{AUTISTIC DEVELOPMENTAL FEATURES OF SCHIZOPHRENIA}

The developmental pathological model for schizophrenia was originally established on the basis of the speculated relationships between schizophrenia and some epiphenomena including nonspecific abnormal brain pathologies $[23,24]$. However, both the specific pathological marker and the molecular cause of schizophrenia remain, strictly speaking, unknown [25]. There is also no biological marker for ASD [26]. Recent findings are providing further support for developmental similarities in social cognitive deviations between ASD and schizophrenia, and the developmental trajectory of schizophrenia may be characterized by difficulties in "theory of mind" tasks, poor insight or imagination, low empathy level, weak executive function, failure in social judgments, and delayed language development [27-31]. These characteristics are all associated with the persistent deviations in social communication and social interaction in the standard criteria for ASD. The autistic pattern of social cognition is significant especially in individuals with the negative schizophrenia symptoms [27], and the executive function deviation is correlated with the severity of negative symptoms [30]. In addition, it is also well known that individuals with schizophrenia often display restricted and repetitive patterns of behavior, interests, or activities [32]. These repetitive behaviors in schizophrenia include movement mannerisms, motoric rituals, strong preoccupation with unusual objects, and bizarre habits [32]. A longitudinal cohort study revealed that children with speech delay or rituals/habits were more likely to develop psychiatric experiences in early adolescence [22]. The diagnosed ASD cases, which were found in individuals with schizophrenia, have a significant tendency to be Asperger syndrome and to have atypical age of ASD manifestation [33].

The most unique and potentially meaningful develop- mental property of autistic cognition is savant skill. The estimated prevalence of the cognitive superiority in ASD varies from $10 \%$ to surprising numbers [34-36]. This discrepancy among estimations could be explained by the presence of high intelligence autistic individuals with low IQ [37]. Regardless of the IQ level, autistic individuals may possess high processing speed, prodigious memory capacities, and heightened primary sensory processing [37-39]. These cognitive superiorities are believed to have the same origin as the social difficulties in ASD [40], and the term, "autistic savant skills", is used to describe one of the core cognitive features of ASD $[37,41]$. Importantly, creative people with high intelligence have an elevated risk for developing certain forms of psychopathology including schizophrenia [42,43]. To interpret the striking increase of genetic structural variations including copy number variations in the last common ancestor of humans and chimpanzees, an evolutionary tradeoff theory is provided in association with ASD and schizophrenia $[44,45]$. The benefits in the trade-off theory may be something beneficial resulted from expanding the range of genetic diversity [44] or reproductive something beneficial associated with the creativity $[42,46]$.

\section{EPISODIC FEATURES IN INDIVIDUALS WITH AUTISM}

Episodic characteristics or acute exacerbation of behavioral problems should be associated with the personal experiences and environmental changes and can be influenced by the individual background knowledge. Because what we can learn from experience and our responses to environmental changes are highly age-related, episodic contents of a behavioral condition should change by age. In children with ASD, temper tantrums and selfinjurious behaviors correlate with autistic traits [47]. The clinical picture of ASD can change with increasing age and in different circumstances [48], and the behavioral plasticity or behavioral improvement is evident in supportive circumstances in individuals with ASD [26], suggesting possible emergence of age-related problematic episodes in unsupportive circumstances. Hyper- or hyporeactivity to sensory input or unusual interest in sensory aspects of environment, which is introduced in DSM-5 as ASD criteria, may affect the episodic characteristics of ASD. Hypo-prior-based ubiquitous sensitivity in the perceptional Bayesian model [49] may be associated with hyper-arousal conditions with cognitive hypersensitivity in individuals with ASD. Fluctuation of the arousal conditions, which is induced by environmental changes, may also be associated with episodic features in ASD. Both the excessive preoccupation with unusual fantasy worlds in children with ASD and the "withdrawal to fantasy life" in schizophrenia [50] can be referred to as reality 
distortion. The reality distortion might clinically manifest itself or be latent according to the arousal level in perceptual thinkers [20,51]. In adolescents with ASD, not only negative symptoms but also positive schizotypal symptoms including catatonia correlate to ASD symptoms [52-54].

\section{DISCUSSION}

The reconsideration of the categorical identity of schizophrenia was launched in the discussion on the Kraepelinian dichotomy [55]. This traditional dichotomous view of the relationship between schizophrenia and bipolar disorder was challenged by family studies, twin studies, and recent molecular genetic findings [55]. The proposed spectrum from schizophrenia at one end to bipolar disorder at the other was historically suggested by Kraepelin by himself [56], and consequently involved ASD at the position adjacent to schizophrenia in the spectrum [57]. As described above, the developmental pathological model for schizophrenia was originally established on the basis of the speculated relationships between schizophrenia and some epiphenomena including nonspecific abnormal brain pathologies [23,24]. However, both the specific pathological marker and the molecular cause of schizophrenia remain, strictly speaking, unknown [25]. In the developmental hypotheses of schizophrenia, the clinical outcomes were supposed to be mediated by a range of mechanisms including genetic mediation, environmental influences, and individual cognitive experiences [55,57-59], and the childhood origins of schizophrenia were underscored $[58,60]$. It has been repeatedly claimed that ASD and schizophrenia are clinically distinct but have a clear degree of overlap that may reflect shared etiological mechanisms [2,61]. The distinction between ASD and schizophrenia is speculated to be explained by condition-specific genetic factors, molecular networks, brain functions, or neuroanatomical differences [61-63].

To reconsider the genetic and developmental relationships between ASD, schizophrenia, and bipolar disorder, four alternative hypotheses were recently introduced [64]. These are 1) ASD subsumed in schizophrenia, 2) independence, 3) diametric, and 4) partial overlap models. The diametric hypothesis is based on a proposal in which ASD and schizophrenia are distinct and at opposite ends of the same "social brain" spectrum [64]. Importantly, the reverse of the subsumed model is missing from the list. We independently proposed the missing model in which schizophrenia and bipolar disorder are subsumed in ASD [20]. In our hypothesis, we challenged the dogma that schizophrenia is a distinct clinical entity and schizophrenia is supposed to be mere one of the secondary derivative states in individuals with ASD [20]. The sec- ondary derivative states may include schizophrenia, mood disorders, anxiety disorders, stress-related disorders, dissociative disorders, eating disorders, and abuse. The clinical outcomes may be determined by environmental influences and individual cognitive experiences. Because diagnosed ASD resides in the extreme of bell-shaped behavioral dimension that distribute quantitatively [26], the proposed developmental backgrounds for psychotic conditions include both diagnosed and undiagnosed ASD in the extreme. Behavioral or cognitive components of ASD characteristics in individuals with a normal developmental trajectory may also provide the underpinning for the development of psychotic conditions. In DSM criteria, the only distinctive symptom for the additional diagnosis of schizophrenia in individuals with ASD is apparent emergence of reality distortion (delusions or hallucinations). However, misattribution of stressful experiences (one of the inclinations of autistic adolescents) and the perceptual thinking style (one of the autistic characteristic) can constitute the underpinning of the reality distortion [20]. The possibility that schizophrenia is on the autism spectrum was also introduced by King and Lord [21], and Bevan Jones and colleagues explained the association between autistic traits and psychotic experiences by the possibility that ASD is an early precursor of psychotic experiences [22].

\section{CONCLUSION}

This concise review provides recent results of studies in relation to behavioral and cognitive core domains shared between ASD and schizophrenia. Together with the emerging new genetic concepts concerning human behavioral complex traits, the results and constructions may further compel scientists to reconsider the relationship between ASD and psychotic conditions. In addition, the possibility that psychotic conditions are the secondary derivative states in individuals with ASD or in individuals with subclinical ASD components should be constructively examined.

\section{REFERENCES}

[1] Borsboom, D. (2008) Psychometric perspectives on diagnostic systems. Journal of Clinical Psychology, 64, 10891108. doi:10.1002/jclp.20503

[2] Rzhetsky, A., Wajngurt, D., Park, N. and Zheng, T. (2007) Probing genetic overlap among complex human phenoltypes. Proceedings of the National Academy of Sciences of the United States of America, 104, 11694-11699. doi:10.1073/pnas.0704820104

[3] Burmeister, M., Mclnnis, M.G. and Zöllner, S. (2008) Psychiatric genetics: Progress amid controversy. Nature Reviews, 9, 527-540. doi:10.1038/nrg2381

[4] Sebat, J., Levy, D.L. and McCarthy, S.E. (2009) Rare 
structural variants in schizophrenia: One disorder, multiple mutations; one mutation, multiple disorders. Trends in Genetics, 25, 528-535. doi:10.1016/j.tig.2009.10.004

[5] Saus, E., Brunet, A., Armengol, L., Alonso, P., Crespo, J.M., Fernández-Aranda, F., Guitart, M., Martín-Santos, R., Menchón, J.M., Navinés, R., Soria, V., Torrens, M., Urretavizcaya, M., Vallés, V., Gratacòs, M. and Estivill, $\mathrm{X}$. (2010) Comprehensive copy number variant (CNV) analysis of neuronal pathways genes in psychiatric disorders identifies rare variants within patients. Journal of Psychiatric Research, 44, 971-978. doi:10.1016/j.jpsychires.2010.03.007

[6] Awadalla, P., Gauthier, J., Myers, R.A., Casals, F., Hamdan, F.F., Griffing, A.R., Côté, M., Henrion, E., Spiegelman, D., Tarabeux, J., Piton, A., Yang, Y., Boyko, A., Bustamante, C., Xiong, L., Rapoport, J.L., Addington, A.M. DeLisi, J.L., Krebs, M.O. Joober, R., Millet, B., Fombonne, E., Mottron, L., Zilversmit, M., Keebler, J., Daoud, H., Marineau, C., Roy-Gagnon, M.H., Dubé, M.P., Eyre-Walker, A., Drapeau, P., Stone, E.A., Lafrenière, R.G. and Rouleau, G.A. (2010) Direct measure of the de novo mutation rate in autism and schizophrenia cohorts. American Journal of Human Genetics, 87, 316-324. doi:10.1016/j.ajhg.2010.07.019

[7] Duan, J., Sanders, A.R. and Gejman, P.V. (2010) Genome-wide approaches to schizophrenia. Brain Research Bulletin, 83, 93-102. doi:10.1016/j.brainresbull.2010.04.009

[8] Elia, J., Gai, X., Xie, H.M., Perin, J.C., Geiger, E., Glessner, J.T., D’arcy, M., deBerardinis, R., Frackelton, E., Kim, C., Lantieri, F., Muganga, B.M., Wang, L., Takeda, T., Rappaport, E.F., Grant, S.F., Berrettini, W., Devoto, M., Shaikh, T.H., Hakonarson, H. and White, P.S. (2010) Rare structural variants found in attention-deficit hyperactivity disorder are preferentially associated with neurodevelopmental genes. Molecular Psychiatry, 15, 637646. doi:10.1038/mp.2009.57

[9] Gershon, E.S., Alliey-Rodriguez, N. and Liu, C. (2011) After GWAS: Searching for genetic risk for schizophrenia and bipolar disorder. American Journal of Psychiatry, 168, 253-256. doi:10.1176/appi.ajp.2010.10091340

[10] Reiersen, A.M., Constantino, J.N., Volk, H.E. and Todd, R.D. (2007) Autistic traits in a population-based ADHD twin sample. Journal of Child Psychology and Psychiatry, 48, 464-472. doi:10.1111/j.1469-7610.2006.01720.x

[11] Ronald, A., Simonoff, E., Kuntsi, J., Asherson, P. and Plomin, R. (2008) Evidence for overlapping genetic influences on autistic and ADHD behaviours in a community twin sample. Journal of Child Psychology and Psychiatry, 49, 535-542. doi:10.1111/j.1469-7610.2007.01857.x

[12] Lichtenstein, P., Carlström, E., Råstram, M., Gillberg, C. and Anckarsäter, H. (2010) The genetics of autism spectrum disorders and related neuropsychiatric disorders in childhood. American Journal of Psychiatry, 167, 13571363. doi:10.1176/appi.ajp.2010.10020223

[13] Hallett, V., Ronald, A., Rijsdijk, F. and Happé, F. (2011) Disentangling the associations between autistic-like and internalizing traits: a community based twin study. Jour- nal of Abnormal Child Psychology, 40, 815-827. doi:10.1007/s10802-011-9596-1

[14] Taylor, M.J., Charman, T., Robinson, E.B., Plomin, R., Happé, F., Asherson, P. and Ronald, A. (2012) Developmental associations between traits of autism spectrum disorder and attention deficit hyperactivity disorder: A genetically informative, longitudinal twin study. Psychological Medicine. (in Press). doi:10.1017/S003329171200253X

[15] Fan, X., Henderson, D.C., Nguyen, D.D., Cather, C., Freudenreich, O., Evins, A.E., Borba, C.P. and Goff, D.C. (2008) Posttraumatic stress disorder, cognitive function and quality of life in patients with schizophrenia. Psychiatry Research, 159, 140-146. doi:10.1016/j.psychres.2007.10.012

[16] Odent, M. (2010) Autism and anorexia nervosa: Two facets of the same disease? Medical Hypotheses, 75, 79-81. doi:10.1016/j.mehy.2010.01.039

[17] Lugnegård, T., Hallerbäck, M.U. and Gillberg, C. (2012) Personality disorders and autism spectrum disorders: What are the connections? Comprehensive Psychiatry, 53, 333340. doi:10.1016/j.comppsych.2011.05.014

[18] Kohl, S., Heekeren, K., Klosterkötter, J. and Kuhn, J. (2013) Prepulse inhibition in psychiatric disorders: Apart from schizophrenia. Journal of Psychiatric Research, 47, 445-452. doi:10.1016/j.jpsychires.2012.11.018

[19] Kolvin, I. (1971) Studies in the childhood psychoses: I. Diagnostic criteria and classification. British Journal of Psychiatry, 118, 381-384. doi:10.1192/bjp.118.545.381

[20] Morioka, H., Sameshima, H. and Ijichi, S. (2010) A delusion referred to as schizophrenia? British Journal of Psychiatry (eletters). http://bjp.rcpsych.org/content/196/2/92/reply

[21] King, B.H. and Lord, C. (2011) Is schizophrenia on the autism spectrum? Brain Research, 1380, 34-41. doi:10.1016/j.brainres.2010.11.031

[22] Bevan Jones, R., Thapar, A., Lewis, G. and Zammit, S. (2012) The association between early autistic traits and psychotic experiences in adolescence. Schizophrenia Research, 135, 164-169. doi:10.1016/j.schres.2011.11.037

[23] Murray, R.M. and Lewis, S.W. (1987) Is schizophrenia a neurodevelopmental disorder? British Medical Journal, 295, 681-682. doi:10.1136/bmj.295.6600.681

[24] Weinberger, D.R. (1987) Implications of normal brain development for the pathogenesis of schizophrenia. Archives of General Psychiatry, 44, 660-669 .doi:10.1001/archpsyc.1987.01800190080012

[25] Insel, T.R. (2010) Rethinking schizophrenia. Nature, 468, 187-193. doi:10.1038/nature09552

[26] Ijichi, S., Ijichi, N., Ijichi, Y., Sameshima, H. and Morioka, H. (2011) The genetic basis of phenotypic diversity: Autism as an extreme tail of a complex dimensional traits. In: Deutsch, S.I. and Urbano, M.R., Eds., Autism Spectrum Disorders: The Role of Genetics in Diagnosis and Treatment, InTech, Rijeka, Croatia, 83-102. doi:10.5772/19032

[27] Couture, S.M., Penn, D.L., Losh, M., Asolphs, R., Hurley, R. and Piven, J. (2010) Comparison of social cognitive 
functioning in schizophrenia and high functioning autism: More convergence than divergence. Psychological Medicine, 40, 569-579. doi:10.1017/S003329170999078X

[28] Solomon, M., Olsen, E., Niendam, T., Ragland, J.D., Yoon, J., Minzenberg, M. and Carter, C.S. (2011) From lumping to splitting and back again: Atypical social and language development in individuals with clinical-highrisk for psychosis, first episode schizophrenia, and autism spectrum disorders. Schizophrenia Research, 131, 146151. doi:10.1016/j.schres.2011.03.005

[29] Pijnenborg, G.H.M., Spikman, J.M., Jeronimus, B.F. and Aleman, A. (2012) Insight in schizophrenia: Associations with empathy. European Archives of Psychiatry and Clinical Neuroscience. (in Press). doi:10.1007/s00406-012-0373-0

[30] Saleem, M.M., Harte, M.K., Marshall, K.M., Scally, A., Brewin, A. and Neill, J.C. (2013) First episode psychosis patients show impaired cognitive function: A study of a South Asian population in the UK. Journal of Psychopharmacology. (in Press). doi:10.1177/0269881113477746

[31] Lugnegård, T., Hallerbäck, M.U., Hjärthag, F. and Gillberg, C. (2013) Social cognition impairments in Asperger syndrome and schizophrenia. Schizophrenia Research, 143, 277-284. doi:10.1016/j.schres.2012.12.001

[32] Tracy, J.I., de Leon, J., Qureshi, G., McCann, E.M., McGrory, A. and Josiassen, R.C. (1996) Repetitive behaviors in schizophrenia: A single disturbance or discrete symptoms? Schizophrenia Research, 20, 221-229. doi:10.1016/0920-9964(95)00104-2

[33] Hallerbäck, M.U., Lugnegård, T. and Gillberg, C. (2012) Is autism spectrum disorder common in schizophrenia? Psychiatry Research, 198, 12-17. doi:10.1016/j.psychres.2012.01.016

[34] Mawson, M., Soulières, I., Gernsbacher, M.A. and Mottron, L. (2007) The level and nature of autistic intelligence. Psychological Science, 18, 657-662. doi:10.1111/j.1467-9280.2007.01954.X

[35] Rapin, I. and Katzman, R. (1998) Neurobiology of autism. Annals of Neurology, 43, 7-14. doi:10.1002/ana.410430106

[36] Happé, F. (1999) Autism: Cognitive deficit or cognitive style? Trends in Cognitive Science, 3, 216-222. doi:10.1016/S1364-6613(99)01318-2

[37] Scheuffgen, K., Happé, F., Anderson, M. and Frith, U. (2000) High "intelligence”, low "IQ”? Speed of processing and measured IQ in children with autism. Developmental Psychopathology, 12, 83-90. .doi:10.1017/S095457940000105X

[38] Boddaert, N., Barthélémy, C., Poline, J.B., Samson, Y., Brunelle, F. and Zilbovicius, M. (2005) Autism: Functional brain mapping of exceptional calendar capacity. British Journal of Psychiatry, 187, 83-86. doi:10.1192/bjp.187.1.83

[39] McCleery, J.P., Allman, E., Carver, L.J. and Dobkins, K.R. (2007) Abnormal magnocellular pathway visual processing in infants at risk for autism. Biological Psychiatry, 62, 1007-1014.

\section{doi:10.1016/j.biopsych.2007.02.009}

[40] Brosius, J. and Kreitman, M. (2000) Eugenics: Evolutionary nonsense? Nature Genetics, 25, 253. doi:10.1038/76994

[41] Badclock, C. and Crespi, B. (2006) Imbalanced genomic imprinting in brain development: An evolutionary basis for the aetiology of autism. Journal of Evolutional Biology, 19, 1007-1032. doi:10.1111/j.1420-9101.2006.01091.x

[42] Carson, S.H. (2011) Creativity and psychopathology: A shared vulnerability model. Canadian Journal of Psychiatry, 56, 144-153. PMID:21443821

[43] Kyaga, S., Landén, M., Boman, M., Hultman, C.M., Långström, N. and Lichtenstein, P. (2013) Mental illness, suicide and creativity: 40-year prospective total population study. Journal of Psychiatric Research, 47, 83-90. doi:10.1016/j.jpsychires.2012.09.010

[44] Hayden, E.C. (2009) Darwin 200: The other strand. Nature, 457, 776-779. doi:10.1038/457776a

[45] Marques-Bonet, T., Kidd, J.M., Ventura, M., Graves, T.A., Cheng, Z., Hillier, L.W., Jiang, Z., Baker, C., Malfavon-Borja, R., Fulton, L.A., Alkan, C., Aksay, G., Girirajan, S., Siswara, P., Chen, L., Cardone, M.F., Navarro, A., Mardis, E.R., Wilson, R.K. and Eichler, E.E. (2009) A burst of segmental duplications in the genome of the African great ape ancestor. Nature, 457, 877-881. doi:10.1038/nature07744

[46] Pearlson, G.D. and Folley, B.S. (2008) Schizophrenia, psychiatric genetics, and Darwinian psychiatry: An evolutionary framework. Schizophrenia Bulletin, 34, 722-733. doi:10.1093/schbul/sbm130

[47] Dominick, K.C., Davis, N.O., Lainhart, J., Tager-Flusberg, H. and Folstein, S. (2007) Atypical behaviors in children with autism and children with a history of language impairment. Research in Developmental Disabilities, 28, 145-162. doi:10.1016/j.ridd.2006.02.003

[48] Wing, L. (1997) The autistic spectrum. Lancet, 350, 1761-1766. doi:10.1016/S0140-6736(97)09218-0

[49] Pellicano, E. and Burr, D. (2012) When the world becomes "too real": A Bayesian explanation of autistic perception. Trends in Cognitive Science, 16, 504-510. doi:10.1016/j.tics.2012.08.009

[50] Parnas, J. (2011) A disappearing heritage: The clinical core of schizophrenia. Schizophrenia Bulletin, 37, 11211130. doi:10.1093/schbul/sbr081

[51] Bogdashina, O. (2005) Communication issues in autism and asperger syndrome: Do we speak the same language? Jessica Kingsley Publishers, London.

[52] Kakooza-Mwesige, A., Wachtel, L.E. and Dhossche, D.M. (2008) Catatonia in autism: Implications across the life span. European Child \& Adolescent Psychiatry, 17, $327-$ 335. doi:10.1007/s00787-008-0676-X

[53] Spek, A.A. and Wouters, S.G.M. (2010) Autism and schizophrenia in high functioning adults: Behavioral differences and overlap. Research in Autism Spectrum Disorders, 4, 709-717. doi:10.1016/j.rasd.2010.01.009

[54] Barneveld, P.S., Pieterse, J., de Sonneville, L., van Rijn, 
S., Lahuis, B., van Engeland, H. and Swaab, H. (2011) Overlap of autisitic and schizotypal traits in adolescents with autism spectrum disorders. Schizophrenia Research, 126, 231-236. doi:10.1016/j.schres.2010.09.004

[55] Craddock, N. and Owen, M.J. (2005) The beginning of the end for the Kraepelinian dichotomy. British Journal of Psychiatry, 186, 364-366. doi:10.1192/bjp.186.5.364

[56] Crow, T.J. (2008) Craddock \& Owen vs Kraepelin: 85 years late, mesmerized by “polygenes”. Schizophrenia Research, 103, 156-160. doi:10.1016/j.schres.2008.03.001

[57] Craddock, N. and Owen, M.J. (2010) The Kraepelinian dichotomy: Going, going...but still not gone. British Journal of Psychiatry, 196, 92-95. doi:10.1192/bjp.bp.109.073429

[58] Rutter, M., Kim-Cohen, J. and Maughan, B. (2006) Continuities and discontinuities in psychopathology between childhood and adult life. Journal of Child Psychology and Psychiatry, 47, 276-295. doi:10.1111/j.1469-7610.2006.01614.x

[59] Gilmore, J.H. (2010) Understanding what causes schizophrenia: a developmental perspective. American Journal of Psychiatry, 167, 8-10. doi:10.1176/appi.ajp.2009.09111588
[60] Fatemi, S.H. and Folsom, T.D. (2009) The neurodevelopmental hypothesis of schizophrenia, revisited. Schizophrenia Bulletin, 35, 528-548. doi:10.1093/schbul/sbn187

[61] Cheung, C., Yu, K., Fung, G., Leung, M., Wong, C., Li, Q., Sham, P., Chua, S. and McAlonan, G. (2010) Autistic disorders and schizophrenia: Related or remote? An anatomical likelihood estimation. PLoS ONE, 5, e12233. doi:10.1371/journal.pone.0012233

[62] Sugranyes, G., Kyriakopoulos, M., Corrigall, R., Taylor, E. and Frangou, S. (2011) Autism spectrum disorders and schizophrenia: Meta-analysis of the neural correlates of social cognition. PLOS ONE, 6, e25322. doi:10.1371/journal.pone.0025322

[63] Gilman, S.R., Chang, J., Xu, B., Bawa, T.S. Gogos, J.A., Karayiorgou, M. and Vitkup, D. (2012) Diverse types of genetic variation converge on functional gene networks involved in schizophrenia. Nature Neuroscience, 15, 17231728. doi:10.1038/nn.3261

[64] Crespi, B., Stead, P. and Elliot, M. (2010) Comparative genomics of autism and schizophrenia. Proceedings of the National Academy of Sciences of the United States of America, 107, 1736-1741. doi:10.1073/pnas.0906080106 